\title{
Research and Applications of High-voltage Pulse Discharge Crushing
}

\author{
Xiaodong Wang*, Jing Zhu
}

School of Architectural and Civil Engineering, Harbin University of Science and Technology, Heilongjiang 150080, China

Corresponding Author Email: wangxiaodong-hit@126.com

https://doi.org/10.18280/ejee.210205

Received: 12 January 2019

Accepted: 19 March 2019

\section{Keywords:}

high-voltage pulse discharge (HVPD), crushing, engineering applications, fuse explosion method, electrohydraulic effect method

\begin{abstract}
High-voltage pulse discharge (HVPD) is a green, easy-to-operate, energy-saving and efficient technique that has been applied in many engineering fields. To promote the application of the HVPD in the demolition of concrete structures, this paper introduces different types of HVPD crushing techniques and their unique features, sums up the relevant studies on HVPD techniques, and explores the HVPD applications in rock breaking, concrete crushing, oil well deblocking and foundation engineering. In addition, the author pointed out several problems in HVPD crushing techniques: the HVPD crushing devices are too large to transport, the working voltage is excessively high, and the safety and insulation are yet to be improved. All these problems restrain the promotion of the HVPD techniques. Through the analysis, it is suggested that the working voltage should be appropriately reduced, and the discharge frequency should be increased, such as to lower the production cost, enhance operability, and improve engineering application.
\end{abstract}

\section{INTRODUCTION}

Each year, China witnesses the completion of about 2 billion $\mathrm{m}^{2}$ of urban buildings, and the demolition of around 460 million $\mathrm{m}^{2}$ [1]. As urbanization picks up pace, the demolition demand is continuously on the rise. However, the traditional concrete crushing methods, ranging from mechanical crushing to blasting, have many common defects, namely, high cost, long duration and low efficiency. This calls for a green, efficient and energy-saving technology to break the concrete in densely distributed urban buildings.

High-voltage pulse discharge (HVPD) provides an effective solution to the said problem. The HVPD is a technology that accumulates low-power energy over time and releases it within a short period as high-voltage energy. As early as the mid- $20^{\text {th }}$ century, the USSR has applied the HVPD in fields like rock breaking. In the 1970 s, the Tomsk Polytechnic University discovered that the shockwaves generated from high-voltage breakdown of solid materials (e.g. rocks and concrete) can cause material damages [2]. This phenomenon received much attention from both the USSR and the US. The former hailed the HVPD as a major scientific invention after computer and laser.

In recent years, the HVPD has become a research hotspot and proliferated to the civilian industry. There are three main features of this technology. Firstly, the HVPD is a green technology with no noise, dust or harmful gas, which are commonplace in traditional concrete crushing methods. Secondly, the HVPD is easy to operate by common workers. Before HVPD crushing, the operator only needs to place the discharge electrode in the electrolyte of the object, and control the switch to complete the crushing. Thirdly, the HVPD is highly energy-efficient. Compared with the other green crushing methods (e.g. static crushing and electric heating), the HVPD can achieve excellent breaking effect within a short period and at a low energy cost.
This paper reviews the existing studies and sums up the engineering applications of HVPD crushing techniques, shedding light on further application of these techniques in building demolition.

\section{TYPES OF HVPD CRUSHING TECHNIQUES}

The existing HVPD crushing techniques crush the object mainly through fuse explosion, electrohydraulic effect, and direct discharging.

\subsection{Fuse explosion method}

By fuse explosion method, the metal fuse is wound on the drill bit (Figure 1), inserted into the crack of the rock, and connected to the high voltage. Under the enormous current causes, a plasma forms from the fuse and expands at the high temperature. The ensuring explosion in the crack induces powerful shockwaves, which breaks the rock [3].
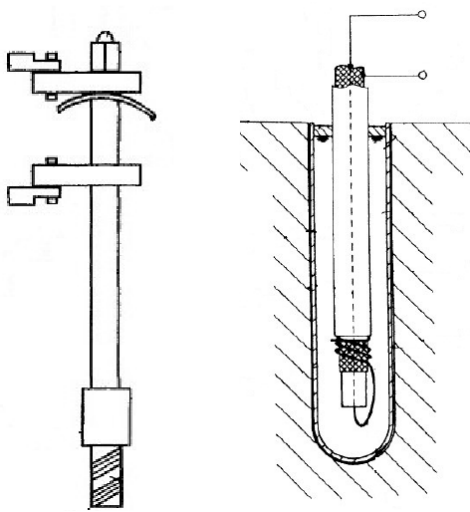

Figure 1. The drill bit of fuse explosion method 


\subsection{Electrohydraulic effect method}

The electrohydraulic effect method was proposed by Yutkin, a scholar of the USSR, and applied by him in pressing, crushing and casting sand cleaning. This technique is implemented in four steps: drilling a hole into the object, adding the electrolyte into the hole, placing the discharge electrode into the electrolyte and introducing the high-voltage current. Under the instantaneous high voltage, electrons and molecules in the electrolyte collide with each other. A plasma will form from the electrolyte and expand due to short-time heating, releasing shockwaves within the limited crack space. The blasting effect is thus achieved [4]. The object crushed by the electrohydraulic effect method is described in Figure 2.

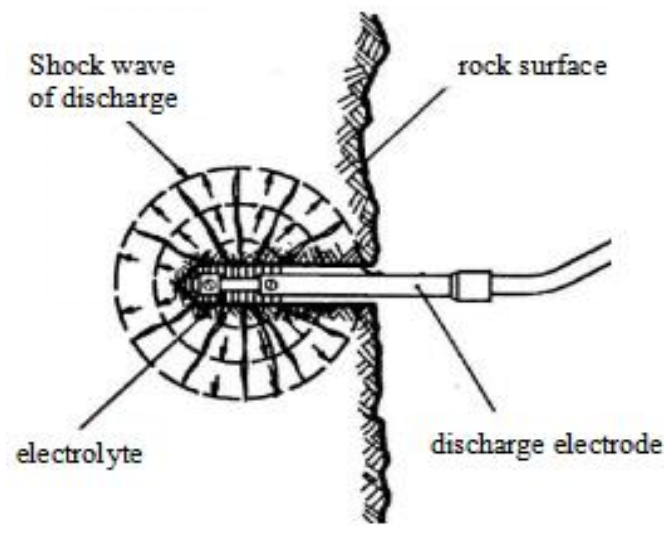

Figure 2. The object crushed by the electrohydraulic effect method

\subsection{Direct discharging method}

By direct discharging method, the object surface is coated with insulating liquid, two electrodes are placed on the surface at a certain spacing, and the high-voltage current is applied. Since the liquid has a stronger breakdown field than brittle materials like rock, the electricity is discharged inside the solid brittle material, causing internal breakdown. The resulting plasma channel will expand instantaneously, turning the object into fragments [5]. The direct discharging method is described in Figure 3.

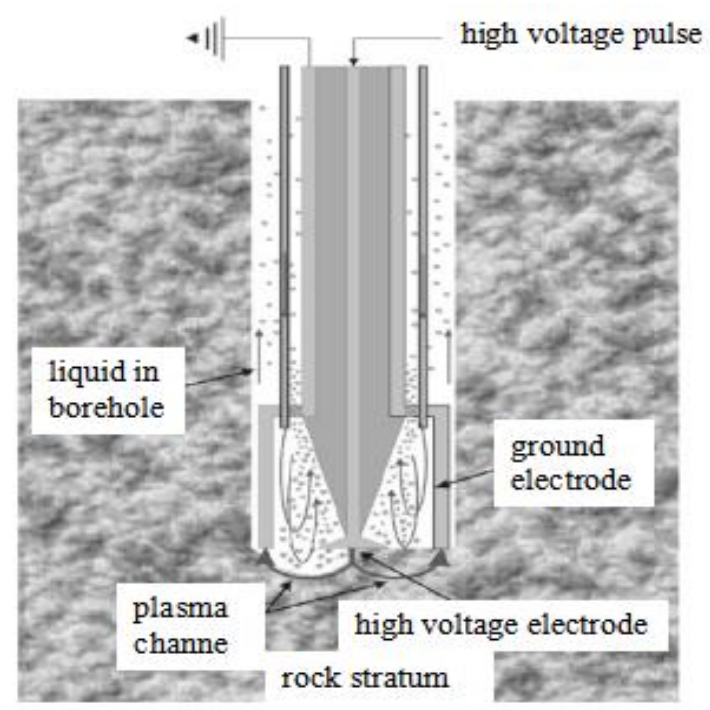

Figure 3. The direct discharging method

\subsection{Comparison between the three methods}

The direct charging method utilizes electrical energy more efficiently than the other two methods. However, it cannot be easily applied to building demolition for the following reasons.

(1) The direct charging method requires an output voltage up to tens or hundreds of kilovolts. Therefore, the equipment components must be high-voltage resistant and highly insulative, making them costly to produce and excessively large in size.

(2) The object should be fully immersed in water, such that the high-voltage breakdown will not occur on the surface. Full immersion is virtually impossible for large building components like concrete structural members.

(3) For concrete structures, the direct charging method can be implemented gradually like rock excavation. However, the gradual implementation is too inefficient for engineering applications.

By contrast, the fuse explosion method and electrohydrualic effect method require a relatively low output voltage. Besides, these two methods support remote controlled discharge crushing after filling up the borehole of the object with electrolyte. As a result, the equipment for the two methods features low cost, high portabiity, as well as easy, safe and reliable operation, and are thus sutiable for building demolition.

Further comparision shows that the fuse explosion method is slightly less practical and efficient than the electrohydraulic effect method. In fuse explosion method, it is difficult to achieve repeated explosions rapidly, as the fuse must be replaced before each explosion. Nevertheless, the fuse explosion method boasts better energy utilization and crushing effect than the electrohydraulic effect method. Hence, these two methods can be selected to demolish concrete structures, in the light of the actual conditions. In this paper, the HVPD crushing techniques are reviewed mainly in the context of these two methods.

\section{EXISTING STUDIES ON HVPD CRUSHING}

\subsection{Relevant studies outside China}

The HVPD crushing theory was prosposed in the 1950s by Prof. Vorobiev at Tomsk Polytechnic University [6]. Soon, the internal breakdown of brittle materials was observed under high voltage, opening a new field of scientific research. Initially, rock-concrete materials weighting up to $1,000 \mathrm{~kg}$ were subjected to HVPD crushing tests. The test results show that the HVPD crushing is energy-efficient, environmentalfriendly, secure and reliable. Unlike explosive blasting, the HVPD crushing does not produce flying fragments. Moreover, the fragments are of moderate size and suitable for transport.

In recent years, developed countries in Europe and North America have invested heavily on HVPD crushing. For instance, Hawrylewicz et al. [7] carried out rock breaking tests by electrohydraulic effect method, in which the specimen was predrilled to reduce the tensile strength of the rock, aiming to ensure uniform directional splitting and improve crushing efficiency.

Singh et al. [8] also conducted rock breaking tests by electrohydraulic effect method, and analyzed how shockwaves pressurize the rock interior, highlighting the importance of the air bubbles in the electrolyte to rock breaking. 
U.T. Andres et al. [9] performed HVPD tests on apatitenephelinite immersed respectively in water and transformer oil, and successfully crushed the rock samples with the diameter of $12 \mathrm{~mm}$ into fragments with the diameter of $1 \mathrm{~mm}$; the test results show that the rocks are crushed more efficiently in water than in transformer oil.

Using the instantaneous high-voltage of $200 \mathrm{kV}$, Andres crushed silicon rods in water into uniform fragments without releasing any pollutants, and minimized the mechanical contact to enhance the quality of polysilicon production and reduce the pollution risk.

The University of Strathclyde also tested HVPD rock breaking on rock-concrete materials, and created pores with a diameter of $25 \sim 50 \mathrm{~mm}$ through micro-discharge.

The Noranda Technology Center applied electrohydraulic effect method in the crushing of rock-concrete materials, created the rock breaking technique called "plasma blasting" (the plasma was formed through the gasification of the electrolyte), and employed the technique in plasma drilling rigs.

Currently, multiple HVPD devices have been developed in Russia, the US and the EU, and the HVPD plasma drilling rigs are being commercialized. In other words, the HVPD crushing techniques are mastered by traditional technological powers and about to be utilized in the industrial sector, that is, HVPD crushers will soon enter industrial mass production.

\subsection{Relevant studies in China}

The research of HVPD crushing started late in China. The preliminary research results are summarized below.

Xi'an Jiaotong University was the first in China to test the HVPD crushing of rock-concrete materials. Important data were accumulated through these tests.

Chen Shihe [10] analyzed the intrinsic factors and external conditions of rock spalling, summed up the principles and methods of rock crushing and drilling by low-temperature plasma, and introduced the excellent rock beaking effect of plasma in mines.

Lu Xinpei et al. [11] released high-voltage current in liquid, measured shockwave velocity by shadowgraph method, and computed the shockwave pressure and bubble rebound pressure through HVPD simulation, revealing that bubble rebound contributes $1 / 4$ of the total pressure; this means the effect of bubble rebound should not be overlooked.

With a self-developed high-voltage discharge device, Zhejiang University [12] experimentally explored the HVPD crushing of rock-concrete materials, and derived how internal breakdown field strength is affected by the type and thickness of the materials.

Sun Bing et al. [13] tested the discharge reaction with a multi-needle-plate pulse discharge reactor containing liquidgas mixture, and thus obtained the empirical formula for impact pressure in liquid.

Shenyang University of Technology [14] carried out a series of concrete failure tests under impact voltage, captured the relationship between breakdown field strength and concrete thickness, and derived the breakdown voltages of concrete with different thicknesses (Table 1). In addition, the impact current generator model was simulated on Matlab, aiming to disclose how the crushing of rocks with similar properties as granite is affected by the loop and charging/discharging parameters of the generator. The research also concludes that the pressure magnitude of the impact fluid is negatively correlated with the width of the discharge pulse, i.e. the frequency of the discharge current.

Table 1. Technical parameters of the HVPD rock driller

\begin{tabular}{ccccccc}
\hline Thickness $(\mathrm{mm})$ & \multicolumn{6}{c}{ Puncture voltage $(\mathrm{kV})$} \\
\hline 5 & 16.3 & 15.8 & 16.1 & 17.2 & 15.5 & 15.8 \\
10 & 28.6 & 30.0 & 32.5 & 26.8 & 32.0 & 29.1 \\
15 & 43.5 & 42.0 & 41.8 & 42.2 & 44.6 & 39.5 \\
20 & 46.4 & 45.2 & 43.6 & 46.2 & 44.2 & 44.0 \\
25 & 50.4 & 48.0 & 48.2 & 48.7 & 47.8 & 46.7 \\
30 & 51.4 & 50.2 & 51.6 & 50.4 & 52.4 & 510 \\
35 & 60.2 & 58.2 & 58.0 & 59.3 & 57.5 & 57.0 \\
\hline
\end{tabular}

$\mathrm{Fu}$ Rongyao at the Chinese Academy of Sciences [15] designed a high-energy arc fracturing device (maximum energy storage: $40 \mathrm{~kJ}$; maximum output voltage: $20 \mathrm{kV}$; maximum discharge current: $70 \mathrm{kA}$ ), used the device to examine the high-energy discharge on two rock-concrete samples. Through the examination, Fu obtained the influence laws of factors like single release energy, number of discharges, texture density, and suggested optimizing the discharge energy in practice to control the size and cost of the device.

Jilin University ordered a HVPD device from Tomsk Polytechnic University. The device, produced by Prof. Zinovye N.T. and Asst. Yushkov A.Yu, is mainly used to expand piles with pulse discharge [16]. As shown in Figure 4, the main technical parameters of the device include: the pulse voltage amplitude of $9 \mathrm{kV}$, the pulse energy of $50 \mathrm{~kJ}$, and the discharge capacitance of $1,200 \mu \mathrm{F}$. Jilin University applied the device in field pile expansion tests, and obtained how pile expansion is affected by pulse discharge energy, number of pulse discharges, as well as the porosity, particle size and water content of the surrounding soil.

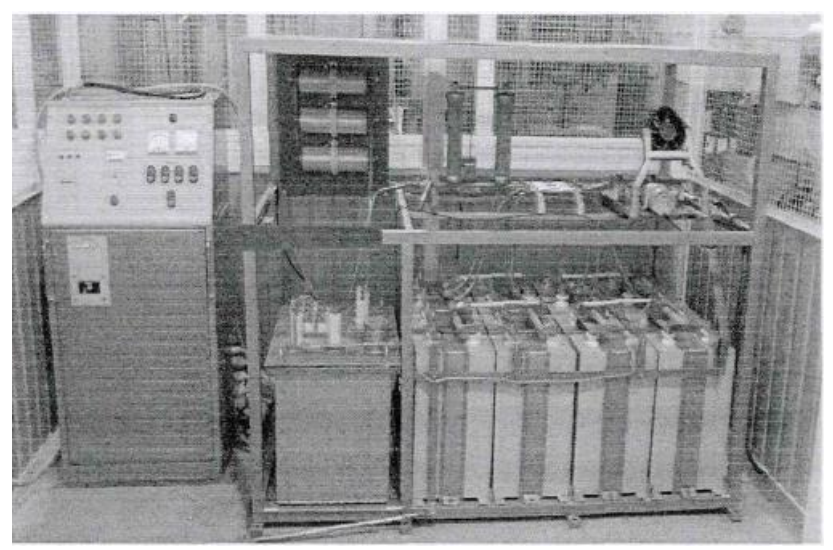

Figure 4. The HVPD pile expansion device

In 2011, the Beijing SHRIMP Center, an affiliate of Institute of Geology, Chinese Academy of Geological Sciences, purchased the first lab-level HVPD crusher in China. The crusher has been installed, debugged and put into normal use as of early 2012. It can release high-voltage current of $90 \sim 200 \mathrm{kV}$, and is provided with a movable container.

At present, the HVPD devices used by Chinese scholars are mostly purchased from abroad or modelled on foreign devices. The research of HVPD crushing in China lags far behind that in western countries. Moreover, there is little report on the application of HVPD in concrete crushing and other aspects of structure demolition. 


\section{ENGINEERING APPLICATIONS OF HVPD DEVICES}

The HVPD rock breaking has been deeply explored outside China, and gradually applied in engineering projects.

\subsection{Concrete crushing}

Early in mid- $20^{\text {th }}$ century, the USSR demolished concrete foundations using the electrohydraulic effect. But this method has not been promoted for various reasons.

Later, the Ukrainian Academy of Sciences developed a crushing device in the light of the electrohydraulic effect. With a frame size of $1.46 \mathrm{~m} \times 1.46 \mathrm{~m} \times 2.10 \mathrm{~m}$, the device has a supply voltage of $380 \mathrm{~V}$, a rated energy storage of $100 \mathrm{~kJ}$, and a rated voltage of $6 \mathrm{kV}$. There is no loud noise, vibration or dust during the operation of the device. The efficiency of the device in removing concrete blocks is $3 \mathrm{~m}^{3} / \mathrm{h}$ [17].

During the use of the above device, Moscow Power Installation Company adopted a new mixed-solvent electrolyte [18]. Under high-voltage discharge, the electrolyte releases extra energy through chemical reactions, which prolongs the impact pressure on concrete structure. There is no time for the shockwave-induced concrete cracks to close. Instead, the cracks are further expanded by the chemical energy, which may also tear the rebars apart. The adoption of the electrolyte increases the concrete removal efficiency to $6 \sim 8 \mathrm{~m}^{3} / \mathrm{h}$.

Bluhm et al. [19] of the Karlsruhe Institute of Technology designed a semi-industrial prototype for concrete crushing and recycling. Taking Marx generator as the high-voltage pulse source, the prototype can output a voltage of $350 \mathrm{kV}$ and a frequency of $10 \mathrm{~Hz}$, and achieve an efficiency of $1,000 \mathrm{~kg} / \mathrm{h}$. With this device, large concrete blocks can be crushed and reused. The prototype and its crushing effect are presented in Figure 5 below.
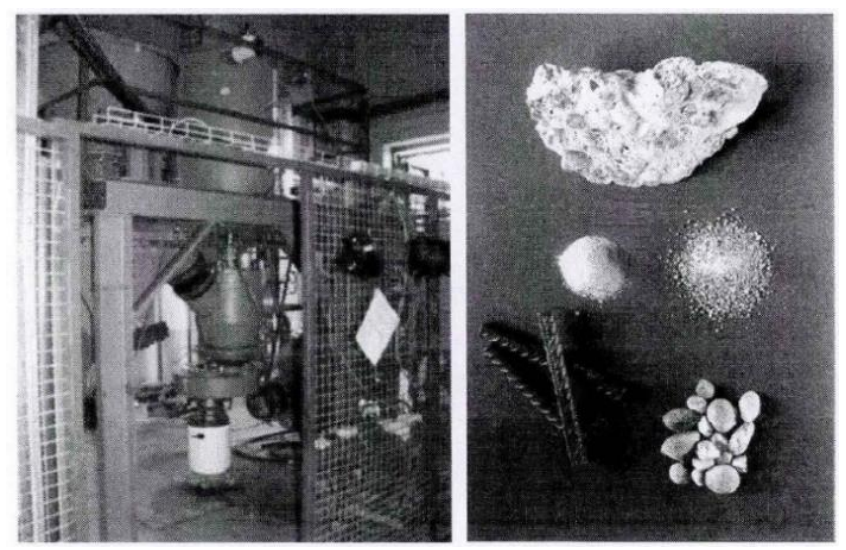

Figure 5. The semi-industrial prototype for concrete crushing and the crushing effect

After 2000, the Russian Academy of Sciences created a HVPD device based on electrohydraulic effect that outputs a maximum current of $180 \mathrm{kA}$. The device can break the concrete by inducing strong shockwaves in predrilled holes. It boasts a great potential in engineering applications.

In 2010, Hitachi Zosen Corporation manufactured the ESG7K2 discharge impact generator (Figure 6). The device has achieved excellent effect in demolition of concrete and masonry structures, the maintenance of roads and bridges, the breaking of rock layers and the cleaning of underwater pollutants. The energy consumption of the device is
$0.1 \sim 0.2 \mathrm{~kW} \cdot \mathrm{h} / \mathrm{m}^{3}$. Each generator can break $70 \sim 80 \mathrm{~m}^{3}$ of rocks per day through HVPD crushing. Meanwhile, the working efficiency of pneumatic pick and manual pick are respectively $5 \sim 20 \mathrm{~m}^{3}$ and $10 \sim 50 \mathrm{~m}^{3}$. Hence, the generator boasts a high efficiency at a low noise [20].
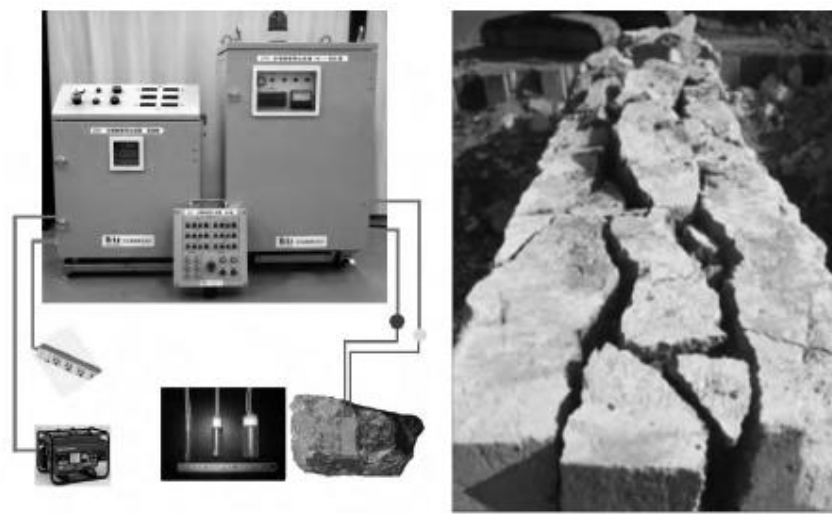

Figure 6. The discharge impact generator and its crushing effect

\subsection{Rock breaking}

In the 1960s, the USSR and the US began to research electrical rock breaking. The Russian Academy of Sciences was the first to develop vehicle-mounted rock breaking equipment and apply it to mining. The Research School of High-Energy Physics, Tomsk Polytechnic University, designed an HVPD drilling rig, which has been adopted in oilfields of Russia and Norway. Russia has also probed deep into HVPD-based rock cutting and hard rock excavation.

In the US, the application of the HVPD in rock breaking can be traced back to 1955. In 2009, the US developed an HVPD drilling rig, which can work with unprecedented efficiency under the voltage up to $100 \mathrm{kV}$. Noranda Technology Center produced a prototype of rock breaker with a 5DOF arm. The rock breaker releases $300 \mathrm{~kJ}$ of energy in each discharge, and handles 3 4 tons of ores after 250 consecutive discharges. NASA relied on HVPD crushing to extract rocks from the moon.

The HVPD rock crusher developed by Karlsruhe research centre has already been sold worldwide. The HVPD crusher produced by Selfrag AG, a swiss company, produces high voltages between 90 and $200 \mathrm{kV}$. The Selfrag HVPD preweakening test station (Figure 7) can handle 10 tons of ores per hour. The HVPD device with a handling capacity of 100 tons per hour will soon be developed.

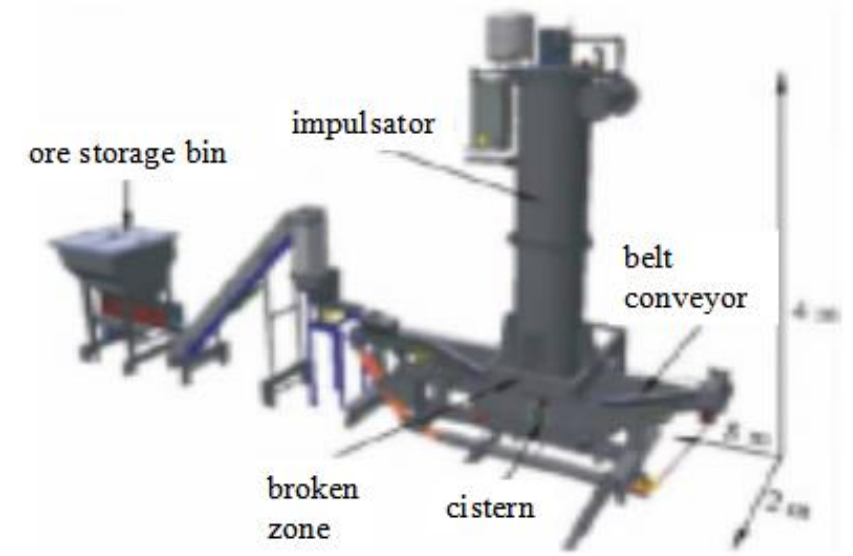




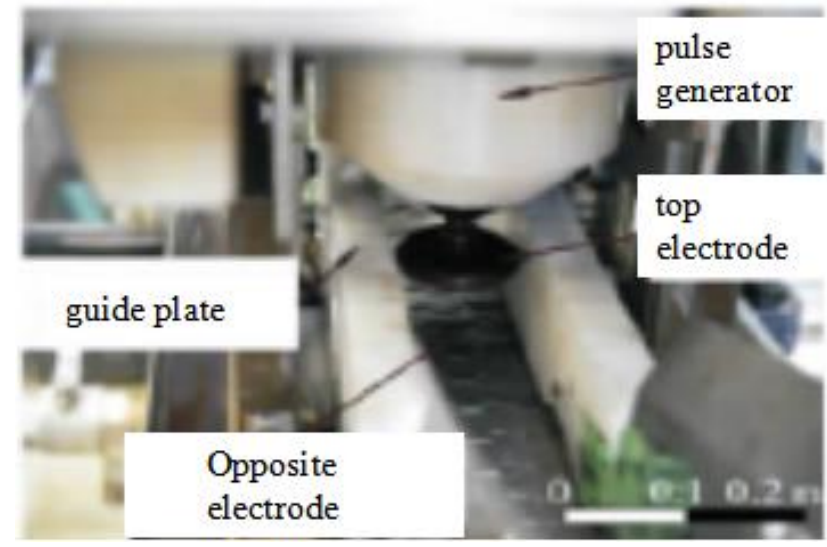

Figure 7. The Selfrag HVPD pre-weakening test station.

According to the applications in rock breaking and drilling, the HVPD crushing is an effective way to improve the efficiency of mining industry.

\subsection{Oil well unblocking}

Since the 1970s, the US and other countries have attempted to solve tubing blockage and formation pollution in oil recovery by HVPD techniques. So far, great breakthroughs have been made in HVPD rock breaking for oil production, and numerous industrial or semi-industrial machines have been developed and utilized. Table 2 lists the technical parameters of several typical HVPD rock breakers [21].

Table 2. The technical parameters of typical HVPD rock breakers

\begin{tabular}{|c|c|c|c|c|c|}
\hline $\begin{array}{l}\text { Location of } \\
\text { equipment }\end{array}$ & Russia & Ukraine & $\begin{array}{l}\text { Tsinghua } \\
\text { University }\end{array}$ & $\begin{array}{c}\text { Chinese } \\
\text { Academy of } \\
\text { Sciences }\end{array}$ & $\begin{array}{c}\text { Xi'an } \\
\text { Jiaotong } \\
\text { University }\end{array}$ \\
\hline $\begin{array}{c}\text { Operating } \\
\text { voltage } / \mathrm{kV}\end{array}$ & 2.5 & 30 & 4 & $4.5 \sim 4.8$ & $25 \sim 30$ \\
\hline $\begin{array}{c}\text { Peak } \\
\text { current } / \mathrm{kA}\end{array}$ & 20 & 9.85 & 6.4 & 22.4 & 30 \\
\hline $\begin{array}{l}\text { Primary } \\
\text { energy/kJ }\end{array}$ & 1.5 & 1 & $2 \sim 2.5$ & $3 \sim 3.5$ & 1.8 \\
\hline $\begin{array}{c}\text { Power } \\
\text { dissipation } / \mathrm{kW}\end{array}$ & 0.3 & 1 & 1.5 & 1 & 1 \\
\hline
\end{tabular}

The USSR developed a complete set of HVPD rock driller, and conducted many field tests with the device. The rock driller has a working voltage of $200 \sim 700 \mathrm{kV}$, a single pulse energy of $0.5 \sim 20 \mathrm{~kJ}$, a required driller diameter of $80 \sim 1,100 \mathrm{~mm}$ and an electrode spacing of $20 \sim 300 \mathrm{~mm}$.

Some Chinese universities, research institutes and enterprises have engaged in the $R \& D$ and industrial application of HVPD devices. For example, Henan Oilfield designed a downhole low-frequency pluse sonometer for oil production. Two such devices were utilized to unblock 40 oil and water wells. Over $80 \%$ of the wells were effectively unblocked. Within the effective period (up to 9 months), the oil production per well increased by more than $40 \%$ [22].

In the early 1990s, the Institute of Electrical Engineering, the Chinese Academy of Sciences, invented a low-frequency pulse wave deplugger. In 1998, this device was adopted by Henan Oilfield in 11 oil wells. The results show that $72 \%$ of the wells were unblocked. The unblocking effect was particularly prominent in three wells. The effect was not significant on the other wells, owing to the small enery output per discharge of the limited energy storage. Later, the device was modified by Exploration and Production Research Institute, Henan Oilfield. The modification mainly increased the effective downhole energy of each pulse. The modified devices was tested in ten wells in the Bi-125 common heavy oil block, Gucheng Oilfield, and proved effectively in 9 tests, putting the success rate at $90 \%$. Through the tests, the cumultative crude oil output grew by $3,463.8$ tons.

Han Bo et al. designed a prototype of large-pulse current discharger for oil well unblocking (energy storage: $2 \sim 5 \mathrm{~kJ}$ ), and tested the device in well G117-8 in Jidong Oilfield. During the test, the device discharged 1,000 pulse currents, each with $2.5 \mathrm{~kJ}$ of energy; the liquid and oil productions of the well increased from 3 tons and 2.1 tons to $22 \sim 3.9$ tons and 13.2 20.1 tons, respectively. The marked increase lasted for over 3 months.

To sum up, the existing HVPD devices generally discharge a high pulse energy every time, which greatly limits the electrode life, energy efficiency, and repeated use of the power source. To solve the problem, the output voltage amplitude should be appropriately reduced to lower the energy release per discharge. The same curshing effect of each discharge should be achieved through multiple discharges with fewer enegy output each time. In this way, the device volume can be reduced, making it easier to transport, the service life can be extended, and the operation safety can be enhanced. With the advancement in microelectronics and electronic equipment manufacturing, the HVPD devices are bound to become more protable and intelligent, and to output currents with even higher frequencies and energies.

\subsection{Foundation pile expansion}

The application of HVPD techniques in foundation engineering have long been studied in the USSR. The earliest research took place in the late 1950s. Some scholars created shockwaves by the electrohydraulic effect method, and applied the shockwaves on saturated sand, making the loose saturated sand particles finer and more compact.

From the late 1970 s to the early 1980 s, the great breakthroughs in HVPD theory and process laid the foundation for a new HVPD device, which was later applied in more than 20 projects in Leningrad (today's St. Petersburg).

In the 1990s, the РИТ company, which specializes in HVPD pile formation, was founded in Russia. The company employed the HVPD pile-forming in 15 projects across Moscow.

By 2003, the HVPD techniques had been adopted in the foundations of over 300 buildings. Many of them are landmarks like the building of the Theatre Union of the Russian Federation, the auxiliary buildings of Bolshoi Theatre, and the teaching building of School 1529, etc. More than 10,000 HVPD-formed piles had been adopted in malls across Russia. The engineering practices confirm the effect and potential of HVPD techniques in foundation engineering.

\subsection{Other engineering applications}

With more in-depth research, HVPD techniques have been introduced to many other fields, including but not limited to waste gas purification with plasma, pulse discharge sewage treatment, electrostatic dust removal, sterilization, ozone production, extracorporeal shock-wave lithotripsy, biological 
medium analysis under pulsed electromagnetic field, geophysical exploration in mines, underwater target detection, high-speed X-ray underwater photography, industrial radiation sources, and rapid heating and quenching.

\section{CONCLUSIONS}

HVPD crushing has attracted much attention by scholars around the world. The existing studies mainly focus on rockbreaking, oil well unblocking and foundation engineering. However, the HVPD theories and devices are gradually maturing, providing a reliable guarantee for the application in building demolition. The HVPD concrete crushing techniques have already been explored in developed countries, and are expected to stand out as competitive demolition methods with high efficiency and greenness.

The existing HVPD devices can achieve reliable crushing performance. But the application of HVPD in building engineering face problems like high production cost and large size. Our analysis shows that the working voltage should be appropriately reduced to lower the energy release per discharge. In this way, the device volume and production cost can be reduced, making it easier to transport and apply in industrial fields.

To date, scholars around the world have had a preliminary understanding of how HVPD device parameters affect the crushing performance, but had not expressed the effects mathematically. In addition, the HVPD crushing techniques are being tested. More research is needed to formulate a complete technical specification for HVPD crushing.

\section{ACKNOWLEDGMENT}

National Key R\&D Program of China (2017YFC0806100).

\section{REFERENCES}

[1] Liu, T.L. (2017). Chinese renewable energy industry regional distribution strategy research. Wuhan University, 3-7.

[2] Kozhevnikov, V.Y., Kozyrev, A.V., Semeniuk, N.S., Kokovin, A.O. (2018). Theory of a high-voltage pulse discharge in a high-pressure gas: Hydrodynamic and kinetic approaches. Russian Physics Journal, 61(2): 603610. https://doi.org/10.1007/s11182-018-1439-x

[3] Owada, S., Suzuki, R., Kamata, Y., Nakamura, T. (2018). Novel pretreatment process of critical metals bearing escrap by using electric pulse disintegration. Journal of Sustainable Metallurgy, 4(2): 157-162. https://doi.org/110.1007/s40831-018-0170-8

[4] Lisitsyn, I.V., Inoue, H., Katsuki, S., Aiyama, H. (1999). Use of inductive energy storage for electric pulse destruction of solid materials. IEEE Transactions on Dielectrics and Electrical Insulation, 6(1): 105-108. https://doi.org/10.1109/94.752017

[5] Yan, F., Lin, B., Zhu, C., Zhou, Y., Liu, X., Guo, C., Zou, Q. (2016). Experimental investigation on anthracite coal fragmentation by high-voltage electrical pulses in the air condition: Effect of breakdown voltage. Fuel, 183: 583592. https://doi.org/10.1016/j.fuel.2016.06.124
[6] Lisitsyn, I.V., Inoue, H., Nishizawa, I., Katsuki, S., Akiyama, H. (1998). Breakdown and destruction of heterogeneous solid dielectrics by high voltage pulses. Journal of Applied Physics, 84(11): 6262-6267. https://doi.org/10.1063/1.368946

[7] Voitenko, N., Yudin, A.S. (2016). Mobile electricdischarge blasting unit for splitting off and destruction of rocks and concrete. Key Engineering Materials, 685: 705-709.

https://doi.org/10.4028/www.scientific.net/KEM.685.70 5

[8] Biela, J., Marxgut, C., Bortis, D., Walter Kolar, J. (2009). Solid state modulator for plasma channel drilling. IEEE Transactions on Dielectrics \& Electrical Insulation, 16(4): 1093-1099. https://doi.org/10.1109/IPMC.2008.4743680

[9] Voitenko, N.V., Yudin, A.S., Kuznetsova, N.S. (2016). Application of electro-discharge blasting technology for destruction of oversized rocks and rock massive splitting off. Key Engineering Materials, 712: 5. https://doi.org/10.4028/www.scientific.net/KEM.712.15

[10] Chen, S.H., Ma, S.R., Zou, W.J. (2006). Application of plasma technology in mines. Uranium Mining and Metallurgy, 25(4): 173-176. https://doi.org/10.3969/j.issn.1000-8063.2006.04.002

[11] Lu, X.P. (2011). Study on the pressure characteristics of pulsed discharge in water. Explosionand Shock Waves, 21(4): 282-286. https://doi.org/10.3321/j.issn:10011455.2001 .04 .008

[12] Zhang, Z.C. (2001). Rock fragmentation by pulsed high voltage discharge and drilling equipment development. Zhejiang: Zhejiang University, 34-65.

[13] Sun, B., Gao Z.Y., Aye N.N., Zhu, X.M., Yan, Z.Y., Song, Y.J. (2013). Generation and transfer characteristics of active substances produced by pulse discharge in multi-needle gas-liquid mixing reactor. High Voltage Engineering, $39(1)$ : $109-116$. https://doi.org/10.3969/j.issn.1003-6520.2013.01.016

[14] Jiang, Q., Xu, Q.F. (2013). Simulation of impulse current generator based on industrial lithotripsy. Journal of Shenyang Ligong University, 32(5): 68-72. https://doi.org/10.3969/j.issn.1003-1251.2013.05.015

[15] Fu, R., Sun, Y., Fan, A., Gao, Y., Yan, P., Zhou, J. (2015). Research of rock fracturing based on high voltage pulse in shale gas drilling. High Power Laser and Particle Beams, 41(12): 4055-4059. https://doi.org/10.13336/j.1003-6520.hve.2015.12.026

[16] Li, D.S. (2001). Experimental research on the mechanism of high-volage pulse discharge pile. Jilin University, 20-47.

[17] Huang, S.L. (1991). Two new technologies used to dismantle old concrete foundation of power station. Heilongjiang Electric Power Technology, 13(3): 184185.

[18] Hamelin, M., Kitzinger, F., Pronko, S., Schofield, G. (1993). Hard rock fragmentation with pulsed power. IEEE Pulsed Power Conference, Albuquerque, 7(11). https://doi.org/10.1109/PPC.1993.512865

[19] Zhang X.R. (2017). Research progress of selfrag high voltage pulse crushing technology. Metal Mine, 3: 97101.

[20] Shi, J.H. (2015). Preliminary discussion on green removal technology for reinforced concrete support. 
Construction Technology, 37(5): 596-598. https://doi.org/10.14144/j.cnki.jzsg.2015.05.028

[21] Sun, Y.H., Sun G.S., Yan, P., Peng, Y.C. (2002). The development of the electric pulse oil-mining technology. High Voltage Engineering, 28(1): 41-42. https://doi.org/10.3969/j.issn.1003-6520.2002.01.020
[22] Zhao H.Y. (2016). A thesis for the master degree of science in engineering. Shenyang: Shenyang Ligong University. 